\title{
Koszty wytwarzania powłok metodami natryskiwania cieplnego
}

\author{
Coating maufacturing costs \\ with the use of thermal spraying methods
}

\section{Streszczenie}

Opisano przeznaczenie i zakres zastosowania powłok natryskiwanych cieplnie. Przedstawiono przybliżoną kalkulację kosztów wytwarzania powłok metodami płomieniowej i elektrycznej metalizacji natryskowej oraz natryskiwania plazmowego. Określono zużycie materiałów powłokowych ( $\mathrm{w} \mathrm{kg} / \mathrm{m}^{2}$ na $0,1 \mathrm{~mm}$ grubości powłoki) przez wprowadzenie współczynnika korygującego stanowiącego stosunek gęstości najczęściej stosowanych materiałów powłokowych względem gęstości stali (przeciętne zużycie stali na wytworzenie powłoki o grubości $0,1 \mathrm{~mm}$ wynosi $1 \mathrm{~kg} / \mathrm{m}$ ) oraz przytoczono ceny (w euro) ważniejszych materiałów powłokowych, zużywanych mediów, energii elektrycznej oraz ludzkiej pracy. Zestawiono wydajność krajowych palników metalizacyjnych (gazowych i elektrycznych) oraz plazmotronu i podajnika proszków oraz uzyskane wyniki pomiarów dotyczące sprawności osadzania się na metalowym podłożu ważniejszych materiałów natryskiwanych plazmowo.

\begin{abstract}
The paper presents the purpose and scope of thermal sprayed coating applications. It shows the approximate cost calculation of producing a coating by flame, electric and plasma spraying. It is specified the consumption of coating materials (in $\mathrm{kg} / \mathrm{m}^{2}$ to $0.1 \mathrm{~mm}$ thickness) by a correction factor which is the ratio of the density of the most commonly used coating materials relative to the density of steel (the average consumption of steel to produce the film with a thickness of $0.1 \mathrm{~mm}$ is $1 \mathrm{~kg} / \mathrm{m}$ ) and quoted prices (in euro) of the most important coating materials consumed media, electricity and labour. It is also summarizes the performance of the domestic torches and guns (gas and electric, the plasmatron and the powder feeders. The results of measurements of the efficiency of deposition on a metal substrate the major plasma sprayed materials are also presented.
\end{abstract}

\section{Wstęp}

Pierwsze prace z zakresu natryskiwania cieplnego powłok dotyczyły wytwarzania warstw z cynku, w celu ochrony przed korozją wyrobów stalowych. Dalszy rozwój metod natryskiwania cieplnego to regeneracja i nadawanie częściowo zużytym, jak i nowo produkowanym elementom maszyn i urządzeń dużej twardości i odporności na zużycie (również w podwyższonej temperaturze) oraz pożądanych właściwości cieplno-optycznych, katalitycznych, elektrycznych itd. Wytwarzanie powłok o tych właściwościach stało się możliwe dzięki użyciu specjalnych materiałów powłokowych i zastosowaniu techniki plazmowej do procesów natryskiwania powłok.

Dr inż. Sławomir Morel - Politechnika Częstochowska.
Przede wszystkim wykorzystuje się trudnotopliwe, supertwarde: węgliki, azotki, borki, tlenki oraz niektóre metale i stopy $z$ tego powodu, że plazma nie nakłada żadnych ograniczeń na temperaturę topliwości stosowanych materiałów, a możliwość jej wytwarzania z dowolnych płynów - na właściwości chemiczne tych materiałów.

Ze względu na wszechstronność zastosowań metody natryskiwania cieplnego (płomieniowego, elektrycznego, plazmowego, laserowego, detonacyjnego itd.) podstawową rolę w kształtowaniu właściwości powierzchniowych wyrobów oraz wytwarzaniu przedmiotów (np. wolframowych dysz silników odrzutowych i rakiet).

Procesy natryskiwania cieplnego mogą być realizowane zarówno w warsztatach, jak i w miejscach eksploatacji urządzeń, bez potrzeby ich demontażu z miejsc a stałej pracy.

Powłoki można nakładać ze wszystkich materiałów, które pod wpływem doprowadzonej energii ulegają stopieniu bądź nadtopieniu. Powłoki natryskiwuje się 
w zasadzie na wszystkie materiały, jak: metale i stopy, ceramikę, szkło, drewno, a nawet wyroby tekstylne.

Wiele zastosowań powłok natryskiwanych cieplnie stwarzają zużywające się elementy maszyn i urządzeń. Ostatnio obserwuje się też intensywny rozwój zastosowań powłok do intensyfikacji procesów wymiany ciepła, dopalania i usuwania trucizn $\left(\mathrm{NO}_{\mathrm{x}}\right)$.

\section{Kalkulacja kosztów wytwarzania powłok}

Obecnie trudne jest zaproponowanie jednoznacznych zaleceń - jakie zastosować materiały, jakiego użyć urządzenia, przy jakich wartościach parametrów realizować procesy natryskiwania, by uzyskać funkcjonalne powłoki. W zakresie kosztów wytwarzania powłok można posługiwać się średnimi cenami zakupu materiałów powłokowych, gazów i energii oraz wynagrodzenia pracowników, które umożliwiają obliczenie kosztów materiałowych i robocizny.

W niniejszym opracowaniu, ze względu na wszechstronność zastosowań metalizacji natryskowej oraz natryskiwania plazmowego (plazma łukowa) w procesach wytwarzania powłok, obliczenia wykonano tylko w odniesieniu do tych metod. W kalkulacji kosztów nie będą uwzględnione: narzuty, koszty administracyjne i zakładowe itd.

\section{Zużycie materiałów na powłoki}

Określenie zapotrzebowania na materiały jest pierwszą czynnością przed wykonaniem kalkulacji, gdyż zużycie materiałów rzutuje na koszty, określa wydajność poszczególnych operacji oraz wyznacza czas niezbędny do przeprowadzenia poszczególnych faz procesu wytwarzania powłok.

Podstawą obliczeń ilości zużytych materiałów są kształt i wymiary natryskiwanej powierzchni. Mnożąc grubość poszczególnych warstw powłoki przez powierzchnię i wartość współczynnika korekcyjnego, określa się potrzebne ilości materiałów na powłoki.

Wartość współczynnika korekcyjnego zależy bezpośrednio od stosunku gęstości właściwej materiałów powłokowych względem gęstości stali, dla której wartość tego współczynnika wynosi 1,0.

Dla najczęściej stosowanych materiałów powłokowych wartości współczynnika korekcyjnego wynoszą odpowiednio, dla: aluminium - 0,5; cynku - 1,0; ołowiu -2,0; molibdenu - 1,0; stali chromowej- 1,0; tlenku aluminium - 0,5; tlenku chromu - 0,7; węglika wolframu - 1,5; węglika chromu - 1,2.

Przez powierzchnię natryskiwanych wyrobów należy rozumieć jej rzeczywistą wartość, na której osadza się powłokę - przykładowo: rzeczywista powierzchnia ściany szczelnej kotła zbudowana w układzie rura-płetwa-rura jest ok. 1,7 raza większa od jej rzutu na powierzchnię.

W przypadkach natryskiwania powłok na elementach małogabarytowych należy uwzględnić straty materiałów, ponieważ szerokość śladu natryskowego wynosi ok. $20 \mathrm{~mm}$ (przy odległości plazmotronu od podłoża ok. $100 \mathrm{~mm}$ ).

Powszechnie przyjmuje się, że do natryskiwania $1 \mathrm{~m}^{2}$ stalowej powłoki zużywa się $1 \mathrm{~kg}$ stali bądź odpowiednio: $0,5 \mathrm{~kg} \mathrm{Al}$ lub $\mathrm{Al}_{2} \mathrm{O}_{3}$, ewentualnie $0,7 \mathrm{~kg} \mathrm{Cr} \mathrm{O}_{3}$ (co wynika z wartości współczynnika korekcyjnego).

Kształt i wymiary natryskiwanej powierzchni oraz parametry procesów natryskiwania decydują o sprawności osadzania natryskiwanych materiałów powłokowych (tabl. I) [1]

Tablica I. Optymalne parametry plazmowego natryskiwania powłok wytwarzanych z użytych w badaniach materiałów powłokowych [1, 4] Table I. Plasma sparying optimal paramters for tested coating materials [1, 4]

\begin{tabular}{|c|c|c|c|c|c|}
\hline \multirow{4}{*}{ Materiał powłokowy } & \multicolumn{4}{|c|}{ Parametry natryskiwania } & \multirow{4}{*}{$\begin{array}{c}\text { Efektywność } \\
\text { osadzania } \\
\text { proszków } \\
\%\end{array}$} \\
\hline & \multirow{2}{*}{ Napięcie/natężenie prądu } & \multicolumn{2}{|c|}{ Zużycie gazów plazmotwórczych } & \multirow{3}{*}{$\begin{array}{c}\text { Odległość plazmotronu } \\
\text { od powierzchni }\end{array}$} & \\
\hline & & $\mathrm{Ar}$ & $\mathrm{H}_{2}$ & & \\
\hline & $\mathrm{V} / \mathrm{A}$ & $\mathrm{dm}^{3} / \mathrm{min}$ & $\mathrm{dm}^{3} / \mathrm{min}$ & & \\
\hline $\begin{array}{c}\mathrm{Al}_{2} \mathrm{O}_{3} \\
\mathrm{Al}_{2} \mathrm{O}_{3}+10 \% \mathrm{NiAl} \\
\mathrm{Al}_{2} \mathrm{O}_{3}+25 \% \mathrm{NiAl} \\
\mathrm{Al}_{2} \mathrm{O}_{3}+40 \% \mathrm{NiAl} \\
\end{array}$ & $\begin{array}{l}55 / 450-500 \\
57 / 450-500 \\
60 / 450-500 \\
60 / 450-500\end{array}$ & $\begin{array}{l}50 \\
50 \\
50 \\
50\end{array}$ & $\begin{array}{c}10 \\
8 \\
7 \\
7\end{array}$ & $\begin{array}{c}130 \\
120 \\
110 \div 120 \\
110 \\
\end{array}$ & $\begin{array}{c}80 \div 85 \\
80 \\
82 \\
87 \\
\end{array}$ \\
\hline $\begin{array}{c}\mathrm{Cr}_{2} \mathrm{O}_{3} \\
\mathrm{Cr}_{2} \mathrm{O}_{3}+10 \% \mathrm{NiAl} \\
\mathrm{Cr}_{2} \mathrm{O}_{3}+25 \% \mathrm{NiAl} \\
\mathrm{Cr}_{2} \mathrm{O}_{3}+40 \% \mathrm{NiAl}\end{array}$ & $\begin{array}{l}60 / 500-550 \\
60 / 450-500 \\
60 / 450-500 \\
60 / 450-500\end{array}$ & $\begin{array}{c}45 \div 50 \\
50 \\
50 \\
50\end{array}$ & $\begin{array}{l}10 \\
12 \\
12 \\
10\end{array}$ & $\begin{array}{c}90 \div 110 \\
110 \\
100 \\
120\end{array}$ & $\begin{array}{c}62 \div 65 \\
67 \\
67 \\
70\end{array}$ \\
\hline $\begin{array}{c}\mathrm{ZrO}_{2} \\
\mathrm{ZrO}_{2}+10 \% \mathrm{NiAl} \\
\mathrm{ZrO}_{2}+25 \% \mathrm{NiAl} \\
\mathrm{ZrO}_{2}+40 \% \mathrm{NiAl}\end{array}$ & $\begin{array}{l}65 / 550-600 \\
65 / 550-600 \\
65 / 550-600 \\
65 / 550-600\end{array}$ & $\begin{array}{l}45 \\
42 \\
42 \\
43\end{array}$ & $\begin{array}{l}15 \\
15 \\
12 \\
14\end{array}$ & $\begin{array}{l}120 \\
120 \\
120 \\
120\end{array}$ & $\begin{array}{c}47 \div 52 \\
51 \\
54 \\
55\end{array}$ \\
\hline $\begin{array}{l}\mathrm{Cr}_{3} \mathrm{C}_{2}+10 \% \mathrm{NiAl} \\
\mathrm{Cr}_{3} \mathrm{C}_{2}+25 \% \mathrm{NiAl} \\
\mathrm{Cr}_{3} \mathrm{C}_{2}+40 \% \mathrm{NiAl}\end{array}$ & $\begin{array}{l}60 / 450-500 \\
60 / 450-500 \\
60 / 450-500\end{array}$ & $\begin{array}{l}45 \\
45 \\
45\end{array}$ & $\begin{array}{l}17 \\
17 \\
18\end{array}$ & $\begin{array}{l}80 \\
80 \\
80\end{array}$ & $\begin{array}{l}89 \\
90 \\
92\end{array}$ \\
\hline
\end{tabular}




\section{Ceny najczęściej stosowanych materiałów powłokowych [2]}

Do dalszych rozważań przyjęto średnie ceny materiałów powłokowych w euro (wg cen z 2005 r.). Wynoszą one:

- stal chromowa: proszek - 54 EUR, drut - 38 EUR,

- stal chromowo-niklowa: proszek - 78 EUR, drut -65 EUR,

- aluminek niklu: NiAl (95-5) proszek - 120 EUR, NiAl (70-30) proszek - 130 EUR, NiAl (80-20) drut - 150 EUR,

- aluminium: drut - 15 EUR

- cynk: drut - 20 EUR

- brąz: drut - 60 EUR,

- węglik wolframu: $W_{2} C$ proszek - 150 EUR, WC proszek - 170 EUR, WC-Co (88-12) proszek - 190 EUR, WC + (NiCrBSi) proszek - 108 EUR,

- węglik chromu: $\mathrm{Cr}_{3} \mathrm{C}_{2}$ proszek - 150 EUR, $\mathrm{Cr}_{3} \mathrm{C}_{2}+\mathrm{Ni}(83-17)$ proszek - $170 \mathrm{EUR}, \mathrm{Cr}_{3} \mathrm{C}_{2}+(\mathrm{Ni}-$ CrBSi) proszek - 140 EUR,

- tlenek glinu: $\mathrm{Al}_{2} \mathrm{O}_{3}+\mathrm{TiO}_{2}$ (87-13) proszek - $80 \mathrm{EUR}$,

- tlenek chromu: $\mathrm{Cr}_{2} \mathrm{O}_{3}$ proszek - $90 \mathrm{EUR}$,

- tlenek cyrkonu: $\mathrm{ZrO}_{2}+\mathrm{MgO}$ (75-25) proszek -80 EUR.

Obecne ceny oraz ceny krajowych materiałów powłokowych mogą istotnie różnić się od wymienionych wartości, są to ceny średnie obliczone na podstawie dostepnych autorowi cenników producentów materiałów przeznaczonych na powłoki.

\section{Koszty wytwarzania}

O wartości kosztów wytwarzania oprócz kosztów materiałów dla przyjętej metody natryskiwania i zastosowanych w związku z tym urządzeń decydują:

- ceny gazów i energii i ich jednostkowe zużycie,

- koszty robocizny,

- koszty ogólne, których wartość może przekroczyć koszty bezpośrednie.

Dla wyszczególnionych urządzeń przytoczono wartości kosztów wynikających ze zużycia gazów, energii elektrycznej i powietrza (tabl. II) [2].

\section{Wydajność natryskiwania}

Wydajność natryskiwania zależy od metody wytwarzania powłok, rodzaju użytych materiałów i wydajności stosowanych urządzeń. Dla krajowych palników i pistoletów metalizacyjnych orientacyjną wydajność podano w tablicy III [3].

Celem wyznaczenia wydajności natryskiwania plazmowego $\mathrm{w} \mathrm{kg} / \mathrm{h}$, należy pomnożyć ilość materiału podawanego przez podajnik proszków (dla pistoletów metalizacyjnych przyjmuje się sprawność $100 \%$ ). Powstała wartość iloczynu wyznacza ilość osadzającego się materiału tworzącego powłokę, w $\mathrm{kg} / \mathrm{h}$ (tabl. IV kol. I).

Tablica II. Koszty gazów, energii elektrycznej, robocizny oraz koszty ogólne dla procesów nakładania powłok różnymi metodami [2]

Table. II. Costs of gases, electric energy, labour and general in different methods of spraying [2]

\begin{tabular}{|c|c|c|c|c|}
\hline \multirow[b]{2}{*}{$\begin{array}{l}\text { Wyszczególnienie } \\
\text { urządzeń, } \\
\text { gazów i ich zużycia }\end{array}$} & \multicolumn{2}{|c|}{ Koszty, EUR } & \multirow[b]{2}{*}{$\begin{array}{l}\text { Roboci- } \\
\text { zna } \\
\text { EUR/h }\end{array}$} & \multirow[b]{2}{*}{$\begin{array}{l}\text { Koszty } \\
\text { ogólne } \\
\text { EUR/h }\end{array}$} \\
\hline & $\begin{array}{c}\text { Cena } \\
\text { jednost- } \\
\text { kowa }\end{array}$ & $\begin{array}{c}\text { Koszt za } \\
\text { godzinę, } \\
\text { eksploatacji }\end{array}$ & & \\
\hline $\begin{array}{l}\text { Obróbka } \\
\text { strumieniowo-ścierna } \\
\text { - kabina } \\
\text { - ø dyszy } 9 \mathrm{~mm} \\
\text { - powietrze } 360 \mathrm{~m}^{3} / \mathrm{h}\end{array}$ & 0,07 & 20 & 25 & 75 \\
\hline $\begin{array}{l}\text { Metalizacja natryskowa } \\
\text { Palnik płomieniowy } \\
\text { - na proszek: tlen } 1 \mathrm{~m}^{3} / \mathrm{h} \\
\text { - acetylen } 1 \mathrm{~m}^{3} / \mathrm{h}\end{array}$ & $\begin{array}{l}2,2 \\
8,5\end{array}$ & $\begin{array}{l}2,2 \\
8,5\end{array}$ & 28 & 75 \\
\hline $\begin{array}{l}\text { Palnik płomieniowy na drut } \\
\text { - powietrze } 60 \mathrm{~m}^{3} / \mathrm{h} \\
\text { - tlen } 1 \mathrm{~m}^{3} / \mathrm{h} \\
\text { - acetylen } 1 \mathrm{~m}^{3} / \mathrm{h}\end{array}$ & $\begin{array}{c}0,07 \\
2,2 \\
8,5\end{array}$ & $\begin{array}{l}4,2 \\
2,2 \\
8,5\end{array}$ & 30 & 75 \\
\hline $\begin{array}{l}\text { Pistolet elekryczny na drut } \\
\text { - energia elektryczna } \\
25 \mathrm{~V}, 400 \mathrm{~A}=10 \mathrm{kWh} \\
\text { - powietrze } 90 \mathrm{~m}^{3} / \mathrm{h}\end{array}$ & $\begin{array}{c}1 \\
0,07\end{array}$ & $\begin{array}{l}10 \\
6,3\end{array}$ & 32 & 70 \\
\hline $\begin{array}{l}\text { Plazmotron } \\
\text { - energia elektryczna } \\
35 \mathrm{~V}, 400 \mathrm{~A}=14 \mathrm{kWh} \\
\text { - azot } 2,5 \mathrm{~m}^{3} / \mathrm{h} \\
\text { - wodór } 0,7 \mathrm{~m}^{3} / \mathrm{h}\end{array}$ & $\begin{array}{c}1 \\
2,0 \\
2,0\end{array}$ & $\begin{array}{c}14 \\
5,0 \\
1,4\end{array}$ & 35 & 85 \\
\hline
\end{tabular}

Tablica III. Wydajność krajowych palników i pistoletów metalizacyjnych [3]

Table III. Efficiency of domestic torches and guns for metalization [3]

\begin{tabular}{|l|c|c|c|c|}
\hline \multirow{2}{*}{\begin{tabular}{l}
\multirow{2}{*}{$\begin{array}{l}\text { Typ i rodzaj } \\
\text { urządzenia }\end{array}$} \\
\cline { 2 - 4 }
\end{tabular}} & \multicolumn{3}{|c|}{$\begin{array}{c}\text { Wydajność natryskiwania, } \\
\mathrm{kg} / \mathrm{h}\end{array}$} & \multirow{2}{*}{ Zutryskiwany metal } \\
\cline { 2 - 4 } & Stal & Aluminium gazów \\
\hline $\begin{array}{l}\text { Palnik } \\
\text { płomieniowy } \\
\text { Metal - 84 (drut) }\end{array}$ & 2,0 & 1,8 & 12,0 & $\begin{array}{l}\text { powietrze } 0,9 \mathrm{~m}^{3} / \mathrm{h} \\
\text { tlen } 1,5 \mathrm{~m}^{3} / \mathrm{h} \\
\text { acetylen } 0,8 \mathrm{~m}^{3} / \mathrm{h}\end{array}$ \\
\hline $\begin{array}{l}\text { Palnik } \\
\text { płomieniowy } \\
\text { PDW - 84 (drut) }\end{array}$ & - & 5,0 & 19,5 & $\begin{array}{l}\text { powietrze } 1,0 \mathrm{~m}^{3} / \mathrm{h} \\
\text { tlen } 2,3 \mathrm{~m}^{3} / \mathrm{h} \\
\text { acetylen } 1,1 \mathrm{~m}^{3} / \mathrm{h}\end{array}$ \\
\hline $\begin{array}{l}\text { Pistolet } \\
\text { elektryczny } \\
\text { BM - G 84 }\end{array}$ & $5 \div 15$ & $2,5 \div 8,5$ & $4 \div 20$ & $\begin{array}{l}\text { powietrze } 1 \mathrm{~m}^{3} / \mathrm{h} \\
\text { energia elektryczna } \\
15 \mathrm{kWh}\end{array}$ \\
\hline $\begin{array}{l}\text { Pistolet } \\
\text { elektryczny } \\
\text { BM - G 88 }\end{array}$ & $5 \div 15$ & $2,5 \div 8,5$ & $4 \div 20$ & $\begin{array}{l}\text { powietrze } 1 \mathrm{~m}^{3} / \mathrm{h} \\
\text { energia elektryczna } \\
15 \mathrm{kWh}\end{array}$ \\
\hline
\end{tabular}


Tablica IV. Optymalne parametry eksploatacji podajnika materiałów powłokowych i ich wydajności [1]

Table IV. Optimal paremeters and efficiency of powder feeder [1]

\begin{tabular}{|c|c|c|c|}
\hline $\begin{array}{c}\text { Materiał } \\
\text { powłokowy }\end{array}$ & $\begin{array}{c}\text { Napięcie } \\
\text { prądu } \\
\mathrm{V}\end{array}$ & $\begin{array}{c}\text { Wydatek gazu trans- } \\
\text { portującego proszek } \\
\mathrm{dm}^{3} / \mathrm{min}\end{array}$ & $\begin{array}{c}\text { Ilość podawane- } \\
\text { go materiału } \\
\mathrm{kg} / \mathrm{h}\end{array}$ \\
\hline $\mathrm{Al}_{2} \mathrm{O}_{3}$ & $180 \div 200$ & 20 & 2,64 \\
$\mathrm{Al}_{2} \mathrm{O}_{3}+10 \% \mathrm{NiAl}$ & $150 \div 170$ & $16 \div 17$ & 1,32 \\
$\mathrm{Al}_{2} \mathrm{O}_{3}+25 \% \mathrm{NiAl}$ & 160 & $15 \div 16$ & 1,34 \\
$\mathrm{Al}_{2} \mathrm{O}_{3}+40 \% \mathrm{NiAl}$ & 160 & 14 & 1,50 \\
\hline $\mathrm{Cr} \mathrm{O}_{3}$ & $160 \div 180$ & 15 & 1,53 \\
$\mathrm{Cr}_{2} \mathrm{O}_{3}+10 \% \mathrm{NiAl}$ & 150 & $16 \div 17$ & 1,44 \\
$\mathrm{Cr}_{2} \mathrm{O}_{3}+25 \% \mathrm{NiAl}$ & 150 & 15 & 1,34 \\
$\mathrm{Cr}_{2} \mathrm{O}_{3}+40 \% \mathrm{NiAl}$ & 150 & 15 & 1,28 \\
\hline $\mathrm{ZrO}$ & $160 \div 170$ & 18 & 1,36 \\
$\mathrm{ZrO}_{2}+10 \% \mathrm{NiAl}$ & 150 & 18 & 1,50 \\
$\mathrm{ZrO}_{2}+25 \% \mathrm{NiAl}$ & 150 & 18 & 1,65 \\
$\mathrm{ZrO}_{2}+40 \% \mathrm{NiAl}$ & 150 & 18 & 1,60 \\
\hline $\mathrm{Cr}_{3} \mathrm{C}_{2}+10 \% \mathrm{NiAl}$ & 160 & 20 & 1,45 \\
$\mathrm{Cr}_{3} \mathrm{C}_{2}+25 \% \mathrm{NiAl}$ & 160 & 21 & 2,61 \\
$\mathrm{Cr}_{3} \mathrm{C}_{2}+40 \% \mathrm{NiAl}$ & 160 & 20 & 2,50 \\
\hline
\end{tabular}

By wyznaczyć wartość wydajności natryskiwania powłoki danym rodzajem materiału powłokowego ( $w \mathrm{~m}^{2} / \mathrm{h}$ ) należy pomnożyć ilość osadzającego się materiału $\mathrm{w} \mathrm{kg} / \mathrm{h}$ przez wartość współczynnika korekcyjnego dla tego materiału.

Otrzymana wartość dotyczy wydajności natryskiwania powłoki $\left(\mathrm{w} \mathrm{m}^{2} / \mathrm{h}\right)$ o grubości $0,1 \mathrm{~mm}$. W celu wyznaczenia wydajności natryskiwania powłoki o pożądanej grubości (np. 0,3 mm) należy otrzymany wynik (wyrażony $\mathrm{w} \mathrm{m}^{2} /(\mathrm{h} \bullet 0,1 \mathrm{~mm})$ podzielić przez grubość powłoki, a ściślej przez hipotetyczną) liczbę warstw o grubości $0,1 \mathrm{~mm}$ (tj. 3).

Otrzymuje się więc wydajność na godzinę natryskiwania danej powłoki o pożądanej grubości. Umożliwia to wyznaczenie niezbędnego czasu do wykonania powłoki na przedmiocie (elemencie) o znanej powierzchni.

\section{Literatura}

[1] Morel S.: Opracowanie i wdrożenie technologii plazmowego natryskiwania powłok. Sprawozdanie z pracy BZ - $12-8 / 86$ - CPBR 2.4. Politechnika Częstochowska 1990, niepublikowane.

[2] Smolka K.: Natryskiwanie cieplne. Poradnik dla praktyków Seria Techniki spawalnicze, t. 15, Dusseldorf 1985.

[3] Brennek J.: Nowe pistolety do natryskiwania cieplnego. Materiały Konferencyjne SITPH, Komitet Eksploatacji Maszyn i Urządzeń EKSPLOHUT’ 88, Beskid Śląski 1988.

[4] Morel S.: Powłoki natryskiwane cieplnie, Wyd. Politechniki Częstochowskiej, Częstochowa 1997.

[5] Morel S.: Application of plasma-sprayed coatings in heat absorption by radiated walls. Archiwum Energetyki tom XLI nr 3-4/2011 s. 111-126.

[6] Morel S.: Zastosowanie powłok w hutniczych urządzeniach grzewczych. Hutnik, Wiadomości Hutnicze nr 5/2011 s. $449-452$.

\section{Spotkania Spawalników w 2012}

\section{Warmińsko-Mazurska Biesiada Spawalnicza}

Piaski k. Ruciane-Nida, 13-14.06.2012, Ośrodek Exploris.

Zgłoszenia i informacje: Mirosława Reschke, tel.: 585112801

\section{Dolnośląskie Sympozjum Spawalnicze}

Wrocław, 20.06.2012, Wydział Mechaniczny Politechniki Wrocławskiej.

Zgłoszenia i informacje: Artur Lange, e-mail: Artur.Lange@pwr.wroc.pl

\section{Szczecińskie Seminarium Spawalnicze}

Szczecin, 6.09.2012, Wydział Inżynierii Mechanicznej i Mechatroniki Zachodniopomorskiego Uniwersytetu Technologicznego w Szczecinie. Zgłoszenia i informacje: Katarzyna Rudzka, tel.: 914624451

\section{Pomorskie Spotkanie Spawalników}

Gdańsk, 13.09.2012, Wydział Mechaniczny Politechniki Gdańskiej.

Zgłoszenia i informacje: Iwona Janson, tel.: 585112800

\section{Kieleckie Spotkanie Spawalników}

Kielce, 20.09.2012, Zakład Doskonalenia Zawodowego w Kielcach.

Zgłoszenia i informacje: Ewelina Janus, tel.: 413687480 w. 102

\section{Organizatorzy}

Linde Gaz Polska, Esab, Abicor-Binzel, Lincoln Electric, Technika Spawalnicza w Poznaniu, Urząd Dozoru Technicznego,

Supra-Elco, Rywal-RHC, Belse, 3M, GCE, Eckert AS, Figel, Witt, Spaw-Ekspert, Trumf, Messner Eutectic Castolin

Materiały konferencyjne zawierające m.in. wybrane artykuły ze spotkań zostaną opublikowane w numerze 10/2012 miesięcznika naukowo-technicznego Przegląd Spawalnictwa 